\title{
Effect of Exercise and Respiratory Training on Clinical Progression and Survival in Patients with Severe Chronic Pulmonary Hypertension
}

\author{
Ekkehard Grünig ${ }^{a} \quad$ Nicola Ehlken ${ }^{a} \quad$ Ardeschir Ghofrani $^{f} \quad$ Gerd Staehler $^{d}$ \\ F. Joachim Meyer ${ }^{b}$ Jana Juenger ${ }^{c}$ Christian F. Opitz ${ }^{i}$ Hans Klose $^{g}$ \\ Heinrike Wilkens $^{\text {h }}$ Stephan Rosenkranz ${ }^{j}$ Horst Olschewskik $^{k}$ Michael Halank $^{\mathrm{e}}$ \\ ${ }^{a}$ Center for Pulmonary Hypertension, Thoracic Clinic, and Departments of ${ }^{\mathrm{b}}$ Cardiology and ${ }^{\mathrm{c} P s y c h o s o m a t i c}$ \\ Medicine, University of Heidelberg, Heidelberg, Departments of Pneumology, ${ }^{\mathrm{d} C l i n i c}$ Löwenstein, Löwenstein, and \\ Universities of ${ }^{\mathrm{e}}$ Dresden, ${ }^{\mathrm{f}} \mathrm{Giessen},{ }^{\mathrm{g}} \mathrm{Hamburg}$ and ${ }^{\mathrm{h}} \mathrm{Homburg}$, and Departments of Cardiology, ${ }^{\mathrm{i}} \mathrm{DRK}$ Kliniken Berlin \\ Köpenick, Berlin, and jUniversity of Cologne, Köln, Germany; ${ }^{\text {K}}$ Division of Pulmonology, Medical University Graz, \\ Graz, Austria
}

\section{Key Words}

Cardiac rehabilitation - Exercise training $\cdot$ Pulmonary

hypertension $\cdot$ Safety $\cdot$ Survival

\begin{abstract}
Background: Even though specific agents for the treatment of patients with pulmonary hypertension $(\mathrm{PH})$ are available, in $\mathrm{PH}$ patients, physical capacity and quality of life (QoL) are often restricted and survival is reduced. Objectives: This study prospectively investigated the long-term effects of respiratory and exercise training in patients with severe chronic PH regarding safety, time to clinical worsening and survival. Methods: Fifty-eight consecutive patients with severe $\mathrm{PH}$ on stable disease-targeted medication received exercise and respiratory training in hospital for 3 weeks and continued at home. They were prospectively followed for $24 \pm 12$ months. Primary endpoints were time to clinical worsening and survival. Adverse events and changes in the 6-min walking test, QoL, WHO functional class and gas exchange were secondary endpoints and were evaluated at baseline and at weeks 3 and 15. Results: All patients tolerated the exercise
\end{abstract}

\section{KARGER}

Fax +4161306 1234

E-Mail karger@karger.ch

www.karger.com
(C) 2011 S. Karger AG, Basel

$0025-7931 / 11 / 0815-0394 \$ 38.00 / 0$

Accessible online at:

www.karger.com/res training well without severe adverse events. In week 15 , 6-min walking test results were significantly improved compared to baseline (by $84 \pm 49 \mathrm{~m}, \mathrm{p}<0.001$ ), as well as QoL scores, WHO functional class (from $2.9 \pm 0.5$ to $2.6 \pm 0.6$, $\mathrm{p}<0.01$ ), peak oxygen consumption (from $12.5 \pm 3.0$ to 14.6 $\pm 3.9 \mathrm{ml} / \mathrm{min} / \mathrm{kg}, \mathrm{p}<0.001$ ), heart rate at rest (from $75 \pm 12$ to $61 \pm 18$ beats $/ \mathrm{min}, \mathrm{p}<0.001$ ) and maximal workload (from $65 \pm 21$ to $80 \pm 25 \mathrm{~W}, \mathrm{p}<0.001$ ). Survival at 1 and 2 years was 100 and $95 \%$, respectively. Fifteen events occurred during the follow-up. Conclusion: This study indicates that exercise and respiratory training as add-on to medical treatment may improve exercise capacity and QoL, and that they have a good long-term safety in the described setting.

Copyright $\odot 2011$ S. Karger AG, Basel

\section{Introduction}

Chronic pulmonary hypertension $(\mathrm{PH})$ is associated with impaired exercise capacity, quality of life (QoL) and survival $[1,2]$. Within the last decade, new disease-targeted medical therapies have been approved for treatment of 
pulmonary arterial hypertension $(\mathrm{PAH})$, such as intravenous epoprostenol, inhaled iloprost, subcutaneously and intravenously administered treprostinil, the endothelinreceptor antagonists bosentan, sitaxsentan and ambrisentan, and the phosphodiesterase type 5 inhibitors sildenafil and tadalafil [3-5]. Combinations of these agents have been shown to further improve symptoms, exercise capacity and QoL in PAH patients [6-9]. However, despite optimized medical therapy patients are still far from their normal exercise capacity and survival rate, with an annual mortality rate of approximately $5-10 \%[10-14]$ or even higher [10]. In patients with non-idiopathic forms of $\mathrm{PAH}$, the outcome of disease has been less well characterized. Long-term effects of novel medical therapies are still unknown. The only prospective, randomized trials to demonstrate a favorable impact on mortality in $\mathrm{PAH}$ patients have been performed using continuous intravenous epoprostenol [11]. The distance walked in $6 \mathrm{~min}$ [15] and QoL [16] represent surrogate markers of survival since they are strongly, independently associated with mortality in PAH patients. In a recent study, we have demonstrated that carefully monitored exercise and respiratory training as add-on to optimized medical therapy improve the 6-min walking distance and QoL in patients with severe PH [17]. Exercise capacity, peak oxygen uptake, workload at anaerobic threshold, maximum heart rate and systolic pulmonary artery pressure at rest improved as well, indicating a reduction in right ventricular work [17]. The increase in the 6-min walking distance following 15 weeks of exercise training was $96 \pm 61 \mathrm{~m}$, being greater than that achieved with $\mathrm{PH}$-specific medical therapy [17]. Exercise training in $\mathrm{PH}$ has also been shown to improve exercise endurance and quadriceps muscle strength [18].

However, although these previous studies $[17,18]$ in a limited number of patients may indicate that exercise and respiratory training are useful adjunctive therapies to $\mathrm{PH}$ [19], so far no data in a larger patient cohort or long-term data are available. In progressive disease, exercise training may even reduce survival, as seen in a recent study of exercise training in monocrotaline-induced $\mathrm{PH}$ in rats [20]. Therefore, the aim of this prospective study was to evaluate whether the positive effects of exercise training on physical capacity and QoL can be repeated in a larger patient cohort, and whether an exercise program is safe in the long term, results in persistent improvement in cardiopulmonary function or at least does not reduce survival or time to clinical worsening.

Effect of Exercise and Respiratory

Training on $\mathrm{PH}$

\section{Patients and Methods}

\section{Study Population and Design}

This prospective study investigated consecutive patients with severe chronic $\mathrm{PH}$ and right heart failure between January 2003 and April 2007 (inclusion and follow-up time) who received exercise and respiratory training as add-on to disease-targeted medication. Further inclusion criteria were age between 18 and 80 years and World Health Organization (WHO) functional class II-IV. Patients had to be stable and compensated with optimized medical therapy (endothelin antagonists, iloprost, sildenafil, anticoagulants, diuretics and supplemental oxygen) for at least 3 months before entering the study. The diagnosis was established at the participating $\mathrm{PH}$ centers according to current guidelines [1, 3]. All patients underwent a detailed clinical workup including right heart catheterization. Testing for vasoreactivity and left heart catheterization were performed when clinically indicated. Sixty-one patients were included in the study; 3 had to be excluded due to the following reasons: in 1 'PAH' patient, echocardiography at baseline revealed severe atypical mitral stenosis, and pulmonary hemodynamics improved after cardiac surgery; 1 patient discontinued due to familial reasons, and 1 patient had to adjust $\mathrm{PH}$-specific medication 1 week before he was scheduled for the training program. Thus, the final training group consisted of 58 consecutive patients who were prospectively followed for $24 \pm$ 12 months. The patients had been referred from 9 centers. They were assessed clinically at baseline and 3 and 15 weeks after the start of exercise training and followed thereafter by regular clinical visits and/or phone contact for $24 \pm 12$ months (fig. 1). All patients gave written informed consent for this study, which was approved by the Ethics Committee of the University of Heidelberg.

\section{Methods}

Efficacy parameters were prospectively evaluated at baseline and after 3 and 15 weeks, as described previously [17]. The 6-min walking test (6MWT) was carried out in a large hall under standardized conditions [21]. Health-related QoL assessment was performed by the Short-Form Health Survey (SF-36) [22]. The results of the SF-36 questionnaire obtained at baseline were compared to those obtained after 15 weeks. 6MWT, SF-36 and other efficacy parameters were assessed by investigators who were blinded to the clinical data of the patients. Changes in WHO functional classification, Borg dyspnea index (with 6 representing no exertion and 20 maximal exertion) [23] and gas exchange were also analyzed [24]. Cardiopulmonary exercise testing was carried out during supine bicycle exercise, as described previously [17]. Workload, heart rate, ventilation $(\mathrm{VE})$, oxygen uptake $\left(\mathrm{VO}_{2}\right)$ and carbon dioxide output $\left(\mathrm{VCO}_{2}\right)$ were measured continuously. The anaerobic threshold was detected with the V-slope method [24]. Further follow-up with evaluation of safety, survival and predefined events indicating clinical worsening was performed by regular control assessments within the participating centers, phone interview and review of the patients' clinical records.

\section{Exercise Training Program}

Exercises and respiratory training were performed as described before [17] and started in the Koenigstuhl Clinic in Heidelberg within the first 3 weeks of rehabilitation. The program consisted of daily interval bicycle ergometer training at low 
Fig. 1. Study population and design: from January 2003 to April 2007, 61 patients with severe chronic $\mathrm{PH}$ were consecutively included in the training group. Three of the 61 patients had to be excluded, 58 were prospectively followed for $24 \pm 12$ months.

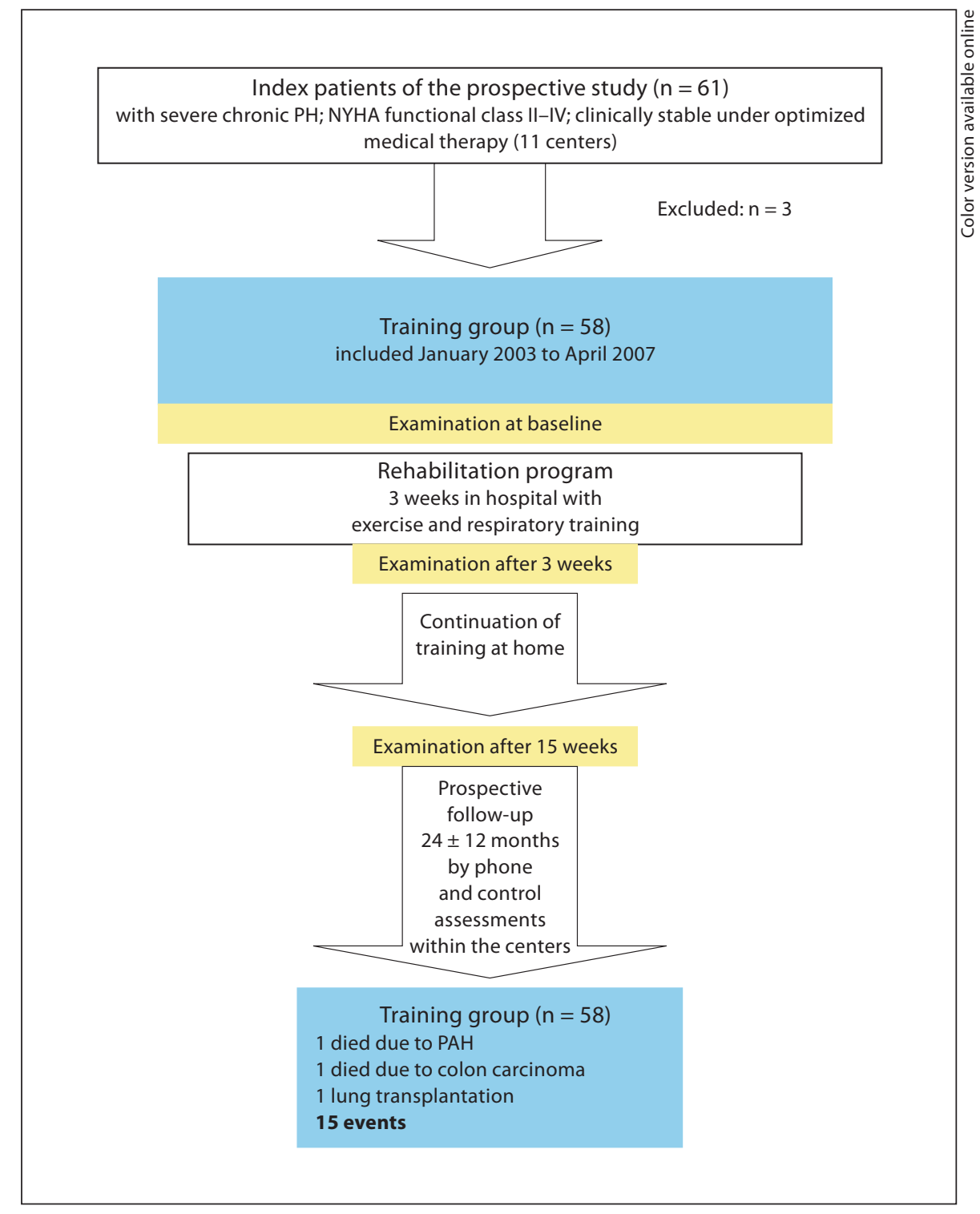

workloads as well as walking, dumbbell training of single muscle groups using low weights (500-1,000 g) and respiratory training (5 days/week). Furthermore, mental training to improve the patients' perception of their individual physical abilities and limits was performed. The program was closely supervised by physical therapists and physicians, as described before [17]. Oxygen saturation and heart rate were monitored continuously throughout the training and were used to adjust the training intensity. When patients' oxygen saturation fell below $85 \%$ with exercise, they received supplemental oxygen $(3-6 \mathrm{l} / \mathrm{min})$ during the training. Twenty-one patients who were already on oxygen therapy (16$24 \mathrm{~h} /$ day) prior to inclusion into this study remained on oxygen throughout the training program. At discharge from the hospital after 3 weeks, patients of the training group received an individualized training manual and ordered a bicycle ergometer for use at home. The amount of training at home was supervised by phone every 2-4 weeks by physiotherapists and/or physicians. During the home-based respiratory and exercise training, all patients were asked to keep close contact to the physicians of the training program and to their general practitioners and specialized center.

\section{Statistical Methods}

Data are given as means $\pm \mathrm{SD}$. Intragroup comparisons (baseline vs. 3 and 15 weeks) were conducted by a paired, two-sided Student's t test for 6MWT, workload, gas exchange and heart rate. WHO functional class and Borg dyspnea index were analyzed by Wilcoxon's rank test. Total scores and subscores of the SF-36 questionnaire were compared by ANOVA and two-tailed Student's t test. $\mathrm{p}<0.05$ was considered statistically significant. Bonferroni 
Table 1. Demographics and baseline characteristics

\begin{tabular}{|c|c|}
\hline Characteristics & $\begin{array}{l}\text { Training } \\
\text { group }\end{array}$ \\
\hline Patients, $\mathrm{n}$ & 58 \\
\hline Females/males & $42 / 16$ \\
\hline Age, years & $51 \pm 12$ \\
\hline Height, cm & $168 \pm 9$ \\
\hline Weight, kg & $72 \pm 12$ \\
\hline \multicolumn{2}{|l|}{ WHO functional class, $\mathrm{n}$} \\
\hline I & 0 \\
\hline II & 10 \\
\hline III & 44 \\
\hline IV & 4 \\
\hline \multicolumn{2}{|l|}{ Combination therapy } \\
\hline Monotherapy & 38 \\
\hline Dual therapy & 18 \\
\hline Triple therapy & 2 \\
\hline \multicolumn{2}{|l|}{ Cause of $\mathrm{PH}, \mathrm{n}$} \\
\hline \multicolumn{2}{|l|}{$\mathrm{PAH}$} \\
\hline Idiopathic PAH & 37 \\
\hline Familial PAH & 3 \\
\hline \multicolumn{2}{|l|}{ PAH associated with } \\
\hline Collagen vascular disease & 2 \\
\hline Congenital systemic to pulmonary shunts & 1 \\
\hline Portal hypertension & 3 \\
\hline $\mathrm{HIV}$ & 1 \\
\hline \multicolumn{2}{|l|}{$\mathrm{PH}$ associated with } \\
\hline Chronic obstructive pulmonary disease & 1 \\
\hline Interstitial lung disease & 2 \\
\hline CTEPH & 6 \\
\hline Others & 2 \\
\hline Walking distance at $6 \mathrm{~min}, \mathrm{~m}$ & $440 \pm 90$ \\
\hline \multicolumn{2}{|l|}{ Cardiac catheterization } \\
\hline Mean PAP, mm Hg & $51 \pm 15$ \\
\hline PVR, dyn $\cdot \mathrm{s} \cdot \mathrm{cm}^{-5}$ & $854 \pm 367$ \\
\hline Cardiac index, $1 / \mathrm{min} / \mathrm{m}^{2}$ & $2.2 \pm 0.7$ \\
\hline
\end{tabular}

Values are means \pm SD. CTEPH $=$ Chronic thromboembolic $\mathrm{PH} ; \mathrm{PAP}=$ pulmonary artery pressure $\mathrm{PVR}=$ pulmonary vascular resistance.

adjustment for multiple comparisons was performed for 6-min walking distances and QoL parameters.

Survival and time to clinical worsening (event-free survival) were estimated by the Kaplan-Meier method using a stratified log-rank test for group comparisons. The start of rehabilitation was used as the index date for determining survival or time to clinical worsening. Clinical worsening was defined as combined endpoint of $\mathrm{PH}$-related death, lung transplantation, hospitalization for $\mathrm{PH}$, clinical worsening leading to initiation of new chronic $\mathrm{PH}$-specific treatment or combined WHO functional classification deterioration and $\mathrm{a} \geq 15 \%$ decrease in $6 \mathrm{MWT}$ from baseline. Patients who had no clinical worsening event were censored at their last follow-up date.

Effect of Exercise and Respiratory Training on $\mathrm{PH}$

\section{Results}

\section{Study Population}

Demographic data, diagnosis, functional class, 6-min walking distance, hemodynamic values and medical therapy are summarized in table 1 . Combination therapies, including two or three $\mathrm{PH}$-specific agents, were used in $35 \%$ of the patients. Most patients (83\%) were in NYHA class III at baseline, with a mean cardiac index of $2.2 \pm$ $0.7 \mathrm{l} / \mathrm{min} / \mathrm{m}^{2}$, indicating a severe form of disease. With respect to the 6-min walking distance at baseline, it has to be kept in mind that this test was performed in a large hall of the rehabilitation clinic Koenigstuhl. All patients had significantly lower 6-min walking distances when measured in their PAH center. Most patients suffered from PAH associated with a variety of conditions (table 1).

\section{Assessment of Training Effects in the Prospectively Followed Training Group}

Compared to baseline, mean 6-min walking distance increased significantly after $3(78 \pm 44 \mathrm{~m})$ and 15 weeks (84 $\pm 49 \mathrm{~m}, \mathrm{p}<0.001$; table 2 ). All patients reported a noticeable improvement in their symptoms. Mean WHO functional class improved significantly from $2.9 \pm 0.5$ to $2.6 \pm 0.6$ after 15 weeks (table 2 ). Mean peak oxygen consumption, peak oxygen uptake in percent of the predicted value and mean $\mathrm{V}^{\prime} \mathrm{E}_{\max }$ increased significantly from baseline to weeks 3 and 15 . The Borg scale remained unchanged, although higher workloads and higher heart rates were attained during exercise (table 2). Exercise and respiratory training significantly reduced heart rate at rest and improved QoL parameters, as indicated by the subscale scores for physical functioning $(\mathrm{p}=0.018)$, role physical $(\mathrm{p}=0.003)$, general health perception $(\mathrm{p}<0.05)$, vitality $(p=0.001)$, social functioning $(p=0.002)$, role emotional $(\mathrm{p}=0.014)$ and mental health $(\mathrm{p}=0.017$; table 2). Using Bonferroni adjustment, p values below 0.016 (6MWT) and 0.005 (SF-36) remained statistically significant.

\section{Outcome}

Overall, 2 of 58 patients of the training group (3.4\%) died during the observation period. One patient died from right heart failure and the other patient died from metastatic colon carcinoma. The probability of survival was 100 and 95\% at 1 and 2 years, respectively (fig. 2). On admission to the exercise training program, 3 of the 58 patients had been listed for lung transplantation. One patient improved markedly and was removed from the 
Table 2. Efficacy parameters of the training group

\begin{tabular}{|c|c|c|c|}
\hline Characteristics & Baseline & After 3 weeks & After 15 weeks \\
\hline 6-min walking distance, $\mathrm{m}$ & $440 \pm 90$ & $518 \pm 93^{* * *}$ & $527 \pm 74^{* * *}$ \\
\hline WHO class & $2.9 \pm 0.5$ & $2.7 \pm 0.5^{* * *}$ & $2.6 \pm 0.6^{* *}$ \\
\hline \multicolumn{4}{|c|}{ Cardiopulmonary exercise testing } \\
\hline Peak $\mathrm{VO}_{2}, \mathrm{ml} / \mathrm{min} / \mathrm{kg}$ & $12.5 \pm 3.0$ & $14.0 \pm 3.6^{* * *}$ & $14.6 \pm 3.9^{* * *}$ \\
\hline $\mathrm{VO}_{2}, \%$ predicted & $51 \pm 13$ & $60 \pm 19^{* * *}$ & $59 \pm 15^{* * *}$ \\
\hline $\mathrm{V}^{\prime} \mathrm{E}_{\max }, 1 / \min$ & $43 \pm 13$ & $50 \pm 16^{* * *}$ & $51 \pm 16^{* * *}$ \\
\hline Workload at AT, W & $49 \pm 17$ & $54 \pm 19^{* *}$ & $61 \pm 22^{* * *}$ \\
\hline $\mathrm{VO}_{2}$ at $\mathrm{AT}, \mathrm{ml} / \mathrm{min}$ & $774 \pm 207$ & $874 \pm 246^{* * *}$ & $884 \pm 252^{* * *}$ \\
\hline $\mathrm{EqCO}_{2}$ at $\mathrm{AT}$ & $48 \pm 12$ & $47 \pm 12$ & $46 \pm 12$ \\
\hline $\mathrm{HR}$ at rest, $\min ^{-1}$ & $75 \pm 12$ & $75 \pm 13$ & $61 \pm 18^{* * *}$ \\
\hline $\mathrm{HR}_{\max }, \min ^{-1}$ & $121 \pm 19$ & $127 \pm 21^{* * *}$ & $131 \pm 19^{* * *}$ \\
\hline Borg & $16 \pm 2$ & $15 \pm 2$ & $15 \pm 2$ \\
\hline Workload, W & $65 \pm 21$ & $76 \pm 26^{* * *}$ & $80 \pm 25^{* * *}$ \\
\hline \multicolumn{4}{|l|}{ SF-36 } \\
\hline Physical functioning & $38.9 \pm 20.7$ & & $52.8 \pm 21.1^{* * *}$ \\
\hline Role physical & $30.0 \pm 38.0$ & & $53.4 \pm 40.2^{* * *}$ \\
\hline General health & $40.6 \pm 16.4$ & & $45.6 \pm 18.3^{*}$ \\
\hline Vitality & $47.1 \pm 17.6$ & & $57.3 \pm 18.4^{* * *}$ \\
\hline Social functioning & $68.3 \pm 24.2$ & & $78.8 \pm 23.6^{* *}$ \\
\hline Role emotional & $68.2 \pm 44.2$ & & $80.1 \pm 32.5^{*}$ \\
\hline Mental health & $64.5 \pm 21.4$ & & $72.6 \pm 15.2^{* * *}$ \\
\hline
\end{tabular}

$\mathrm{AT}=$ Anaerobic threshold; $\mathrm{HR}=$ heart rate. ${ }^{*} \mathrm{p}<0.05,{ }^{* *} \mathrm{p}<0.01,{ }^{* * *} \mathrm{p}<0.001$, vs. baseline.

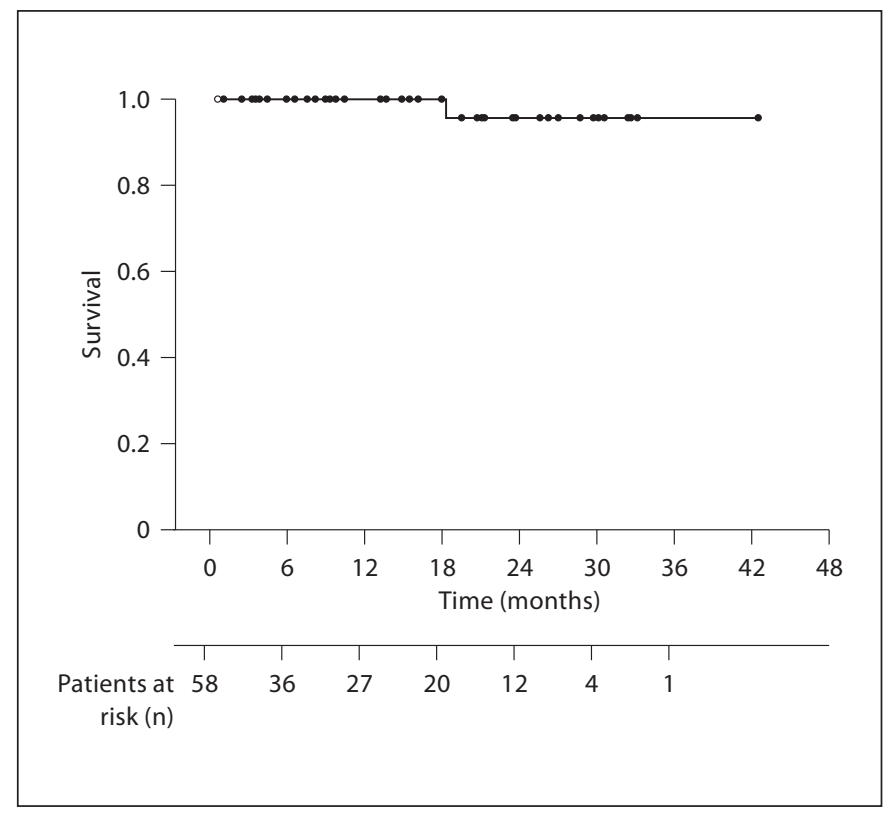

Fig. 2. Survival in the 58 patients of the training group. KaplanMeier curves of survival in patients (n) with severe $\mathrm{PH}$ (functional class III-IV) under optimized medical treatment receiving respiratory and exercise training. + indicates censored cases, logrank test: $\mathrm{p}<0.05$.

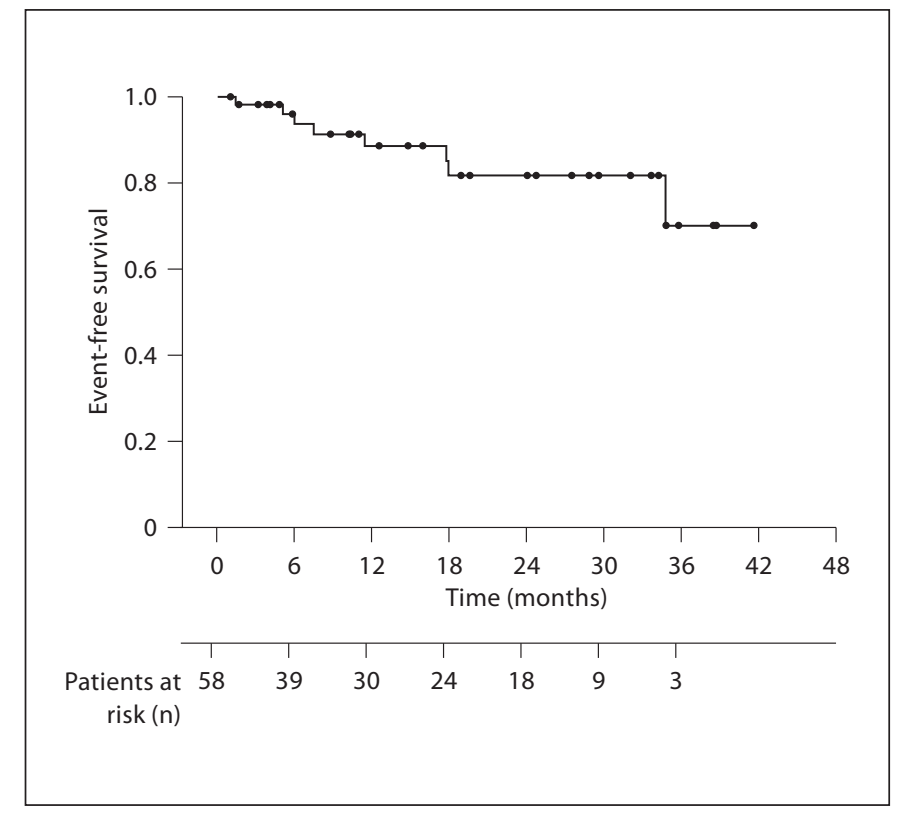

Fig. 3. Time to clinical worsening in the training group. KaplanMeier estimates of time to clinical worsening (event-free survival) of patients with exercise training. + indicates censored cases, logrank test: $\mathrm{p}<0.05$. 
Table 3. Survival and time to clinical worsening

\begin{tabular}{ll}
\hline Characteristics & Training group \\
\hline Patients, $\mathrm{n}$ & 58 \\
Follow-up for survival, months & 42 \\
$\quad$ Mean \pm SD & $24 \pm 12$ \\
Death due to PH, $\mathrm{n}$ & 1 \\
Lung transplantation, $\mathrm{n}$ & 1 \\
Hospitalization, $\mathrm{n}$ & 1 \\
WHO class and 6-min walking distance & 3 \\
$\quad$ deterioration, $\mathrm{n}$ & 9 \\
Initiation of new chronic PH treatment, $\mathrm{n}$ & 15 \\
\hline All events & \\
\hline
\end{tabular}

transplantation list, 1 remained stable until the end of follow-up, and 1 required lung transplantation 18 months later because of clinical worsening.

\section{Time to Clinical Worsening}

During the follow-up, 15 events occurred (fig. 3; table 3): 9 patients received new chronic $\mathrm{PH}$ treatment due to clinical worsening, 3 patients had a deterioration in functional class and 6-min walking distance, 1 patient required in-hospital treatment, 1 patient underwent lung transplantation and 1 patient died.

\section{Safety}

Exercise training was well tolerated by all patients, and there were no severe adverse events such as progression of symptoms, syncope or worsening of right heart failure during the in-hospital program. Two patients experienced a short episode of dizziness without fainting immediately after bicycle ergometer training. During the time in the rehabilitation clinic, exercise training had to be interrupted in 7 patients for 1-2 weeks due to respiratory infections, which were treated with antibiotics. All patients reported that they had improved their awareness of their physical abilities and limitations.

\section{Discussion}

This is the first prospective clinical trial investigating the effects of respiratory and exercise training on physical capacity, long-term safety, time to clinical worsening and survival in patients with severe chronic $\mathrm{PH}$ and right heart failure. After a mean follow-up time of $24 \pm 12$ months, only 1 of 58 patients had died from $\mathrm{PH}$. All patients learned not to overdo themselves and tolerated the training well without severe adverse events. The cardiopulmonary exercise test has become an important clinical tool in the management of patients with pulmonary disease [25-27] or chronic left heart failure (CHF) [28]. Thus, exercise capacity, 6MWT, QoL, WHO functional class, heart rate at rest and parameters of the cardiopulmonary exercise test were assessed and significantly improved after 15 weeks compared to baseline. The results of this study indicate that closely supervised low-dose exercise training may provide a safe and powerful adjunct therapy in patients with severe chronic $\mathrm{PH}$ or at least does not seem to worsen the outcome. A randomized, controlled study is needed to investigate the long-term effect of exercise training on parameters such as QoL, exercise capacity and survival.

The 1- and 2-year survival rates of 100 and 95\%, respectively, observed in the patients of the training group were comparable with those reported in $\mathrm{PH}$ patients receiving medical therapy only. In a controlled trial of an experienced referral center for patients with PAH class III or IV using an advanced therapeutic strategy including combinations of bosentan, sildenafil, inhaled or intravenous iloprost and highly urgent lung transplantation when necessary, survival rates at 1,2 and 3 years were 93.0, 83.1 and 79.9\%, respectively [9]. Comparable 1-, 3and 5-year survival rates of 92,75 and $66 \%$, respectively, have been reported in idiopathic, familial and anorexigen-associated PAH [12-14, 29]. In patients with PAH associated with systemic sclerosis, 1-, 2- and 3-year survival rates were 87,79 and 64\%, respectively [30].

Using a prospective, randomized design, survival rates were studied in $\mathrm{PH}$ patients treated with intravenous epoprostenol [11]. These studies also showed similar survival rates and a similar time to clinical worsening [12]. In our study, we had no comparison to a randomized control group, and the main focus was to evaluate long-term safety of exercise training in this patient cohort. Therefore, further studies are necessary to determine the effects of training programs on the outcome of $\mathrm{PH}$ patients. However, it is a general issue of rehabilitation programs that the therapy cannot be performed in a blinded fashion.

In CHF patients, several studies have suggested that exercise training improves time to clinical worsening and survival $[31,32]$. In patients with CHF due to coronary artery disease, total mortality was reduced by $27 \%$ following exercise training [33]. The reason why exercise training may improve the outcome of patients with chronic left or right heart failure is a matter of speculation. The improved functional capacity after exercise training may be a stimulus for a more active lifestyle that 
contributes to the maintenance of a higher peak $\mathrm{VO}_{2}$. Recent studies in CHF have demonstrated that exercise training can improve neurohumoral and musculoskeletal abnormalities [34], endothelial dysfunction [35] and left ventricular remodeling [36], and has an anti-inflammatory effect [37].

In $\mathrm{PH}$, training showed beneficial effects on right ventricular function and morphology in an animal model [20] and also mitochondrial and microvascular changes in the quadriceps muscle [18]. The improvement in the right ventricular and microvascular function may be a reason for the beneficial effects of the training. The results of our study indicate that supervised respiratory and exercise training improves parameters which have been shown to be prognostically relevant in PAH patients, such as QoL [16], peak oxygen uptake [25] and 6MWT [15]. However, feasibility of this therapy has been questioned for a larger population of patients who have no access to local rehabilitation facilities [19]. Therefore, transformation to an ambulatory outpatient program is warranted. Although no adverse events occurred during this study, we believe that exercise training of $\mathrm{PH}$ patients with right heart failure can be dangerous if it is started and performed by the patients themselves without a very close medical supervision. Nearly all of the patients had initially the tendency to overdo themselves. All patients reported that they had improved their awareness of their physical abilities and limitations within the first 3 weeks of the in-hospital supervision. Especially mental training was therefore an im- portant part of our program. Thus, there may be other long-term benefits of this rehabilitation program unrelated to exercise, including more frequent clinical follow-ups and patient education. We cannot exclude a referral bias since patients could apply to the training program and had to be clinically stable under optimized medical therapy.

\section{Conclusion}

The results of this study suggest that low-dose exercise and respiratory training as add-on to medical therapy result in good long-term safety in a closely supervised setting and may improve exercise capacity and QoL in patients with $\mathrm{PH}$ and right heart failure.

\section{Acknowledgments}

We would like to thank all patients who participated, the $\mathrm{PH}$ e.V. for their support and all physicians, therapists and physiotherapists of the Rehabilitation Clinic Koenigstuhl, Heidelberg, Germany, who took part in the rehabilitation programs.

\section{Financial Disclosure and Conflicts of Interest}

The study was funded by a grant from the German Pulmonary Hypertension Association (Pulmonale Hypertonie e.V.), Rheinstetten, Germany.

\section{References}

$\checkmark 1$ Badesch DB, Champion HC, Sanchez MA, Hoeper MM, Loyd JE, Manes A, McGoon M, Naeije R, Olschewski H, Oudiz RJ, Torbicki A: Diagnosis and assessment of pulmonary arterial hypertension. J Am Coll Cardiol 2009;54:55-66.

2 Rubin LJ: Primary pulmonary hypertension. N Engl J Med 1997;336:111-117.

>3 Galiè N, Hoeper MM, Humbert M, Torbicki A, Vachiery JL, Barbera JA, Beghetti M, Corris P, Gaine S, Gibbs JS, Gomez-Sanchez MA, Jondeau G, Klepetko W, Opitz C, Peacock A, Rubin L, Zellweger M, Simonneau G: Guidelines for the diagnosis and treatment of pulmonary hypertension. Eur Respir J 2009;34: 1219-1263.

-4 Archer SL, Michelakis ED: Phosphodiesterase type 5 inhibitors for pulmonary arterial hypertension. N Engl J Med 2009;361:18641871.
5 Benza RL, Barst RJ, Galie N, Frost A, Girgis RE, Highland KB, Strange C, Black CM, Badesch DB, Rubin L, Fleming TR, Naeije R: Sitaxsentan for the treatment of pulmonary arterial hypertension: a 1-year, prospective, open-label observation of outcome and survival. Chest 2008;134:775-782.

-6 Simonneau G, Rubin LJ, Galiè N, Barst RJ, Fleming TR, Frost AE, Engel PJ, Kramer MR, Burgess G, Collings L, Cossons N, Sitbon O, Badesch DB, PACES Study Group: Addition of sildenafil to long-term intravenous epoprostenol therapy in patients with pulmonary arterial hypertension: a randomized trial. Ann Intern Med 2008; 149:521-530.

7 Benza RL, Rayburn BK, Tallaj JA, Pamboukian SV, Bourge RC: Treprostinil-based therapy in the treatment of moderate-to-severe pulmonary arterial hypertension: longterm efficacy and combination with bosentan. Chest 2008;134:139-145.
-8 O'Callaghan DS, Gaine SP: Combination therapy and new types of agents for pulmonary arterial hypertension. Clin Chest Med 2007;28:169-185.

-9 Hoeper MM, Markevych I, Spiekerkoetter E, Welte T, Niedermeyer J: Goal-oriented treatment and combination therapy for pulmonary arterial hypertension. Eur Respir J 2005;26:858-863.

10 Galiè N, Palazzini M, Manes A: Pulmonary arterial hypertension: from the kingdom of the near-dead to multiple clinical trial metaanalyses. Eur Heart J 2010;31:2080-2086.

11 Barst RJ, Rubin LJ, Long WA, McGoon MD, Rich S, Badesch DB, Groves BM, Tapson VF, Bourge RC, Brundage BH, Koerner SK, Langleben D, Keller CA, Murali S, Uretsky BF, Clayton LM, Jöbsis MM, Blackburn SD, Shortino D, Crow JW: A comparison of continuous intravenous epoprostenol (prostacyclin) with conventional therapy for primary pulmonary hypertension. N Engl J Med 1996;334:296-302. 
12 Galiè N, Rubin Lj, Hoeper M, Jansa P, Al-Hiti H, Meyer G, Chiossi E, Kusic-Pajic A, Simonneau G: Treatment of patients with mildly symptomatic pulmonary arterial hypertension with bosentan (EARLY study): a double-blind, randomised controlled trial. Lancet 2008;371:2093-2100.

13 Langleben D, Cacoub P: A review of STRIDE-2 and STRIDE-2X: the case for selective endothelin receptor blockade. Eur J Clin Invest 2009;39:27-31.

14 Oudiz RJ, Galiè N, Olschewski H, Torres F, Frost A, Ghofrani HA, Badesch DB, McGoon MD, McLaughlin VV, Roecker EB, Harrison BC, Despain D, Dufton C, Rubin LJ, ARIES Study Group: Long-term ambrisentan therapy for the treatment of pulmonary arterial hypertension. J Am Coll Cardiol 2009;54:1971-1981.

-15 Miyamoto S, Nagaya N, Satoh T, Kyotani S, Sakamaki F, Fujita M, Nakanishi N, Miyatake $\mathrm{K}$ : Clinical correlates and prognostic significance of six-minute walk test in patients with cardiopulmonary exercise testing. Am J Crit Care Med 2000;161:487-492.

16 Cenedese E, Speich R, Dorschner L, Ulrich S, Maggiorini M, Jenni R, Fischler M: Measurement of quality of life in pulmonary hypertension and its significance. Eur Respir 2006;28:808-815.

-17 Mereles D, Ehlken N, Kreuscher S, Ghofrani S, Hoeper MM, Halank M, Meyer FJ, Karger G, Buss J, Juenger J, Holzapfel N, Opitz C, Winkler J, Herth F, Wilkens H, Katus HA, Olschewski H, Grunig E: Exercise and respiratory training improve exercise capacity and quality of life in patients with severe chronic pulmonary hypertension. Circulation 2006;114:1482-1489.

18 de Man FS, Handoko ML, Groepenhoff $\mathrm{H}$, van 't Hul AJ, Abbink J, Koppers RJ, Grotjohan HP, Twisk JW, Bogaard HJ, Boonstra A, Postmus PE, Westerhof N, van der Laarse WJ, Vonk-Noordegraaf A: Effects of exercise training in patients with idiopathic pulmonary arterial hypertension. Eur Respir J 2009;34:669-675.
19 Newman JH, Robbins IM: Exercise training in pulmonary hypertension: implications for the evaluation of drug trials. Circulation 2006;114:1448-1449.

20 Handoko ML, de Man FS, Happé CM, Schalij I, Musters RJ, Westerhof N, Postmus PE, Paulus WJ, van der Laarse WJ, VonkNoordegraaf A: Opposite effects of training in rats with stable and progressive pulmonary hypertension. Circulation 2009;120: 42-49.

21 Guyatt GH, Pugsley SO, Sullivan MJ, Thompson PJ, Berman L, Jones NL, Fallen EL, Taylor DW: Effect of encouragement on walking test performance. Thorax 1984;39: 818-822.

22 Ware JE, Sherbourne CD: The MOS 36-item Short-Form Health Survey (SF-36). Med Care 1992;304:73-83.

23 Borg GA: Psychophysical bases of perceived exertion. Med Sci Sports Exerc 1982;14:377381.

24 Wasserman K, Hansen JE, Sue DY, Whipp BJ, Caseburi R: Measurements during integrative cardiopulmonary exercise testing; in Wasserman K, Hansen JE, Sue DY, Whipp BJ, Casaburi R (eds): Principles of Exercise Testing and Interpretation. Philadelphia, Lea \& Febiger, 1994, pp 53-79.

25 Wensel R, Opitz CF, Anker SD, Winkler J, Höffgen G, Kleber FX, Sharma R, Hummel M, Hetzer R, Ewert R: Assessment of survival in patients with primary pulmonary hypertension: importance of cardiopulmonary exercise testing. Circulation 2002;106:319324.

26 Ferrazza AM, Martolini D, Valli G, Palange P: Cardiopulmonary exercise testing in the functional and prognostic evaluation of patients with pulmonary diseases. Respiration 2009;77:3-17.

27 Clini EM, Crisafulli E: Exercise capacity as a pulmonary rehabilitation outcome. Respiration 2009;77:121-128.

28 Piepoli MF: Exercise tolerance measurements in pulmonary vascular diseases and chronic heart failure. Respiration 2009;77: 241-251.
29 Thenappan T, Shah SJ, Rich S, Tian L, Archer SL, Gomberg-Maitland M: Survival in pulmonary arterial hypertension: a reappraisal of the NIH risk stratification equation. Eur Respir J 2010;35:1079-1087.

30 Mathai SC, Hummers LK, Champion HC, Wigley FM, Zaiman A, Hassoun PM, Girgis RE: Survival in pulmonary hypertension associated with the scleroderma spectrum of diseases: impact of interstitial lung disease. Arthritis Rheum 2009;60:569-577.

31 Tabet JY, Meurin P, Driss AB, Weber H, Renaud N, Grosdemouge A, Beauvais F, CohenSolal A: Benefits of exercise training in chronic heart failure. Arch Cardiovasc Dis 2009; 102:721-730.

32 Piepoli MF, Davos C, Francis DP, Coats AJ: Exercise training meta-analysis of trials in patients with chronic heart failure (ExTraMATCH). BMJ 2004;328:189-195.

33 Oldrige NB, Gyatt GH, Fischer ME, Rimm AA: Cardiac rehabilitation after myocardial infarction. Combined experience of randomized clinical trials. JAMA 1988;260: 945-950.

34 Adams V, Doring C, Schuler G: Impact of physical exercise on alterations in the skeletal muscle in patients with chronic heart failure. Front Biosci 2008;13:302-311.

35 Hambrecht R, Fiehn E, Weigl C, Gielen S, Hamann C, Kaiser R, Yu J, Adams V, Niebauer J, Schuler G: Regular physical exercise corrects endothelial dysfunction and improves exercise capacity in patients with chronic heart failure. Circulation 1998;98: 2709-2715.

36 Giannuzzi P, Temporelli PL, Corra U, Gattone M, Giordano A, Tavazzi I: Attenuation of unfavorable remodeling by exercise training in postinfarction patients with left ventricular dysfunction: results of the exercise in left ventricular dysfunction (ELVD) trial. Circulation 1997;96:1790-1797.

-37 Petersen AM, Pedersen BK: The anti-inflammatory effect of exercise. J Appl Physiol 2005;98:1154-1162. 